\title{
CelDi: Development of an Advanced Solid / Fluid Reaction Stage for SEM
}

Johan Salacroup ${ }^{1,2}$, Gautier Gonnet ${ }^{2,3}$, Henri Pierre Brau ${ }^{1}$, Antoine Candeias ${ }^{3}$, Stéphanie Szenknect ${ }^{1}$, Paul Ivaldi ${ }^{2}$ and Renaud Podor ${ }^{1}$

1. Institut de Chimie Séparative de Marcoule, UMR 5257 CEA/CNRS/UM/ENSCM, Site de Marcoule Bât. 426, BP 17171, 30207 Bagnols/Cèze cedex, France.

2. SATT AxLR, 950 Rue Saint-Priest, CSU, Bât. 6, 34090 Montpellier, France.

3. Newtec, 285 Rue Gilles Roberval, Bât. A2 30900 Nîmes, France.

In numerous scientific fields such as life, materials and Earth sciences, or quality controls of industrial processes, there is a growing interest for the direct observation - at the submicroscopic scale - of processes occurring at solid / liquid and solid / gas interfaces. So far, only few experimental cells were designed to address this challenging issue. Most of them are devoted to a specific use in Transmission Electron Microscopy (TEM) and are not suitable for observation of large (or thick) samples and the other cells designed to be used in a Scanning Electron Microscope (SEM) chamber do not allow fluid flow.

To address this issue, a dedicated device was developed according to the following requirements: 1) The sample holder must be suitable for large samples. 2) The device must allow the renewal of the fluid through a continuous flow. 3) The device should be sufficiently efficient and secure to be used in any type of conventional SEM. 4) The device should be easy to implement and user friendly. A first prototype (Fig. 1) was recently tested and patented [1].

For the proof of concept, it was used to perform in situ experiments during which series of images was recorded with a SEM, using the back scattered electron detector, high vacuum in the SEM chamber and e-beam acceleration voltage of $30 \mathrm{kV}$. Fig. 2. presents several images of the growth of $\mathrm{NaCl}$ crystals obtained from a supersaturated solution. The image resolution is good enough to see details of a size of $50 \mathrm{~nm}$. The liquid system that is inside the stage remained isolated from the SEM chamber during the complete experiment.

The CelDi project aims at the development of the second generation of this tool, integrating more safety protections, increasing the resolution of the images, finding solutions to achieve an easy and friendly use of the device. It will be possible to integrate a specific and fast BSE detector in combination with the stage, and work is under progress to develop automatized image processing through dedicated software.

In parallel, several tests will be carried out for different scientific applications in material science (corrosion) and life science (observation of live cells) to demonstrate the capabilities of the CelDi device.

\section{References:}

[1] R. Podor, S. Szenknect, H. P. Brau, J. Ravaux, J. Salacroup. Cellule de suivi de réaction solideliquide ou solide-gaz pour microscope électronique à balayage. Patent n ${ }^{\circ}$ FR 1559465 (05/10/2015). 

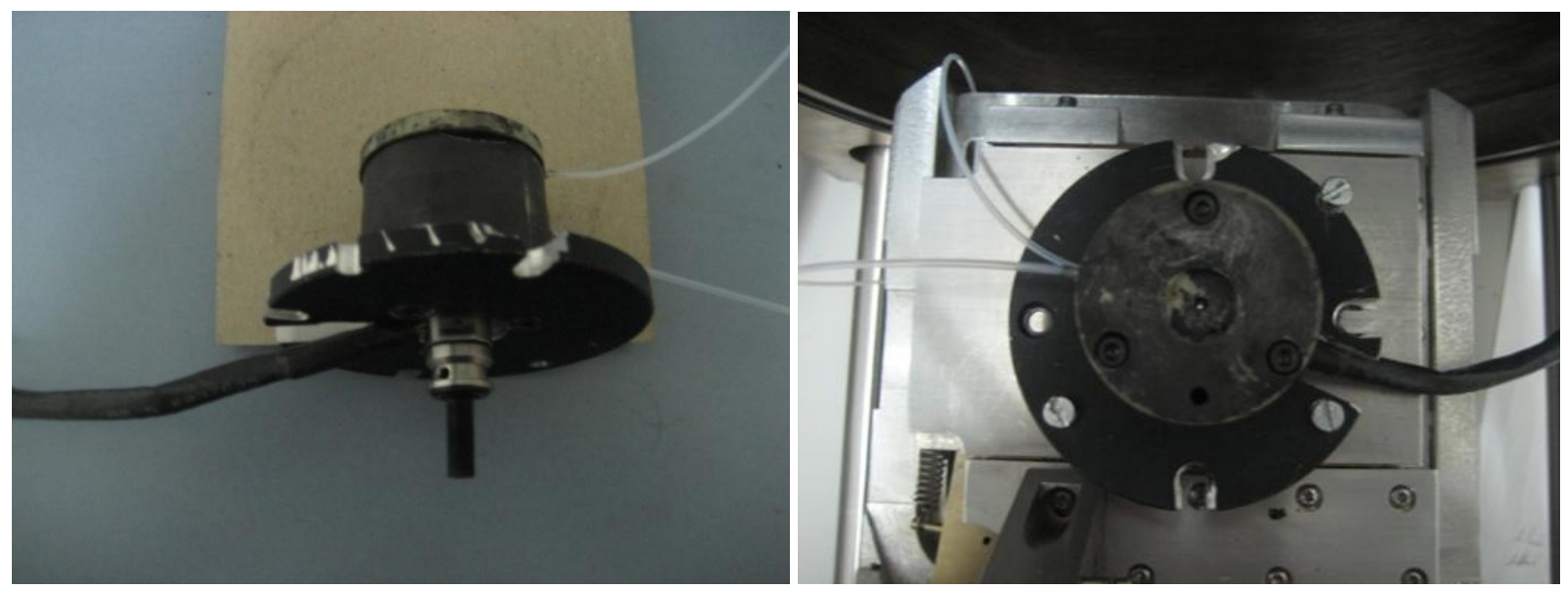

Figure 1. Side and top views of the first CelDi prototype.

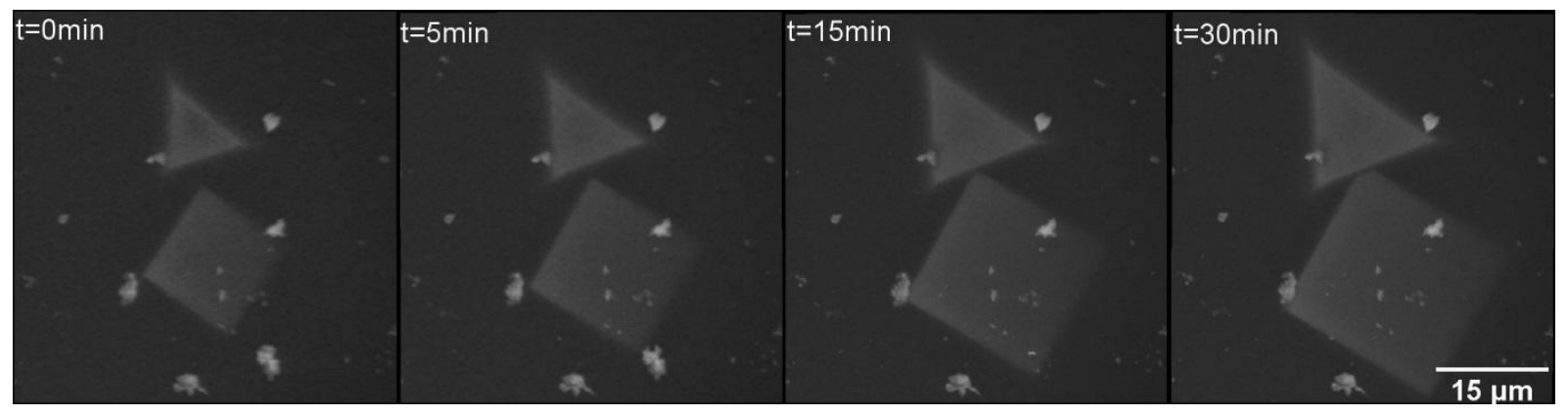

Figure 2. In situ formation and growth of $\mathrm{NaCl}$ crystals in the CelDi stage. White zones are $\mathrm{Nd} 2 \mathrm{O} 3$ particles used as markers. 